\title{
Extratos vegetais do gênero capsicum com potencial atividade antifúngica contra Rhizoctonia solani e Sclerotium rolfsii
}

O uso excessivo de fungicidas na agricultura tem sido bastante questionado pela sociedade em geral em função destes serem caros, de elevada persistência no solo e de elevado risco à saúde humana e ao meio ambiente. Nesse sentido medidas alternativas de controle tem sido buscadas. O presente estudo teve como objetivo avaliar a eficiência de diferentes extratos de sementes de pimentas do gênero Capsicum sobre o crescimento micelial de Rhizoctonia solani e Sclerotium rolfsii. O delineamento experimental foi o inteiramente casualizado com 25 tratamentos, tendo dois controles (água e fungicida) e quatro repetições para os testes in vitro e seis para in vivo. Os dados foram submetidos à análise de Scott Knott a $5 \%$ de probabilidade. Os testes in vitro evidenciaram que todos os extratos se mostraram eficientes na inibição dos patógenos, destacando-se os extratos de Capsicum annuum, os quais obtiveram resultados significativamente superiores ao controle com o fungicida. Nos ensaios em diluição seriada, observou-se que na concentração de até $1 \times 105$ os extratos foram capazes de inibir o patógeno $S$. rolfsii. No ensaio in vivo em folhas destacadas, 13 extratos apresentaram eficiência no controle da mela, sendo que os extratos obtidos a partir de Capsicum baccatum e Capsicum frutescens apresentaram efeitos de controle semelhantes ao fungicida.

\section{Plant extracts of the capsicum genus with potential antifungal activity against Rhizoctonia solani and Sclerotium rolfsii}

\begin{abstract}
The excessive use of fungicides in agriculture has been widely questioned by society at large in functions considered expensive, of high soil persistence and of high risk to human health and the environment. In this sense, alternative control measures were sought. This study aimed to evaluate the efficiency of different Capsicum pepper seed extracts on the mycelial growth of Rhizoctonia solani and Sclerotium rolfsii. The experimental design was randomly isolated with 25 controls, with two controls (water and fungicide) and four replicates for in vitro and six for in vivo tests. Data were analyzed by Scott Knott with a $5 \%$ probability. In vitro tests showed that all extracts are effective in inhibiting pathogens, especially Capsicum annuum extracts, which are the results obtained superior to the controls with fungicide. In serial dilution assays, the concentration is reduced to $1 \times 105$ extracts were able to inhibit the pathogen S. rolfsii. No in vivo assay on detached leaves, 13 extracts reduced the control of the molasses, and the extracts were captured from Capsicum baccatum and Capsicum frutescens, control effects related to fungicides.
\end{abstract}

Keywords: Alternative control; Phytopathogens; Fungal diseases.

Topic: Microbiologia Agrícola e Ambiental

Reviewed anonymously in the process of blind peer.
Received: 05/12/2019

Approved: 15/01/2020
Aline Souza da Fonseca (iD

Universidade Federal de Rondônia, Brasil http://lattes.cnpq.br/0456233723446786 http://orcid.org/0000-0002-4019-3412

alinesouzadafonseca@gmail.com

Cléberson de Freitas Fernandes (iD)

Embrapa Agroindústria Tropical, Brasil

http://lattes.cnpq.br/7426209328649448

http://orcid.org/0000-0001-5269-1139

cleberson.fernandes@embrapa.br

José Roberto Vieira Júnior

Embrapa Rondônia, Brasil

http://lattes.cnpq.br/9904275274067824

http://orcid.org/0000-0001-7939-8119

jose-roberto.vieira@embrapa.br

\author{
Rodrigo Barros Rocha \\ Embrapa Rondônia, Brasil \\ http://lattes.cnpq.br/8295625748916004 \\ rodrigo.rocha@embrapa.br \\ Tamiris Chaves Freire (it) \\ Embrapa Rondônia, Brasil \\ http://lattes.cnpq.br/4372408393666360 \\ http://orcid.org/0000-0002-8938-3751 \\ tamirischavesfreire@gmail.com \\ Simone Carvalho Sangi \\ Embrapa Rondônia, Brasil \\ http://lattes.cnpq.br/6013814953613677 \\ http://orcid.org/0000-0001-7365-015X \\ simonecarvalhosangi@gmail.com
}

\author{
Jéssica Silva Félix Bastos (it) \\ Embrapa Rondônia, Brasil \\ http://lattes.cnpq.br/0634812827491159 \\ http://orcid.org/0000-0001-8009-979X \\ jessicafelixbio@gmail.com \\ Rita de Cássica Alve \\ Universidade Federal de Rondônia, Brasil \\ http://lattes.cnpq.br/6159264388864891 \\ rita diggory@hotmail.com
}

Referencing this:

FONSECA, A. S.; FERNANDES, C. F.; VIEIRA JÚNIOR, J. R.; ROCHA, R. B. FREIRE, T. C.; SANGI, S. C.; BASTOS, J. S. F.; ALVES, R. C.. Extratos vegetais do gênero capsicum com potencial atividade antifúngica contra Rhizoctonia solani e Sclerotium rolfsii. Revista Ibero Americana de Ciências Ambientais, v.11, n.1, p.89-98, 2020. DOI: http://doi.org/10.6008/CBPC2179-6858.2020.001.0010 


\section{INTRODUÇÃO}

O Brasil é o terceiro maior produtor de feijão do mundo ficando atrás apenas de Myanmar e Índia. Já entre os países do MERCOSUL ele ocupa a primeira posição tanto em produção quanto em consumo (FAO, 2017). Algumas doenças estão entre os fatores que reduzem a produtividade e prejudicam a qualidade dos produtos agrícolas. Na cultura do feijoeiro podemos destacar a Mela do feijoeiro, causada pelo fungo Thanatephorus cucumeris (Frank) Donk (anamorfo Rhizoctonia solani Kühn), e a podridão do colo causada pelo fungo Sclerotium rolfsii Sacc. (anamorfo Aetholia rolfsii) importantes doenças ocorrentes na região Amazônica (SARTORATO et al., 2003; RAVA, 2011).

O controle dos fitopatógenos na agricultura é realizado na maioria das vezes com a aplicação de agrotóxicos de alta periculosidade, o que constituiu atualmente em um grande problema de saúde pública devido aos altos índices de contaminação (MACÊDO et al., 2018; RIGOTTO et al., 2014). A busca por novos agentes antimicrobianos extraídos a partir de plantas vem aumentando nos últimos tempos, com isso a utilização de extratos vegetais vem apresentando uma opção promissora para o manejo integrado de pragas que pode contribuir para a redução de doses e aplicações de agrotóxicos (SANTOS et al., 2015).

Um alto número de espécies das plantas presentes na natureza apresentam propriedades antifúngicas em seus extratos. Essas propriedades são derivadas de metabólitos secundários sintetizados pelas plantas que atuam como mecanismo de defesa quando as mesmas sofrem a influência dos estímulos ambientais bastante variáveis de natureza química, biológica e fisiológica (SARTORATO et al., 2003; FERNANDES et al., 2009; STANGARLIN et al., 2011). Diante do exposto, objetivou-se avaliar in vitro e in vivo a eficiência de diferentes extratos de pimentas sobre o crescimento micelial de Rhizoctonia solani e Sclerotium rolfsii.

\section{MATERIAIS E MÉTODOS}

Para os ensaios foram utilizadas 23 variedades comerciais de pimenta (Capsicum spp.), pertencentes ao Banco de Germoplasma do Centro Nacional de Pesquisas em Hortaliças da Embrapa - CNPH, sendo estas: Capsicum annuum. var. Malagueta mexicana, jariza, vulcão, jumbinho, pimenta dos desejos, jurema e peito de moça; Capsicum chinense var. biquinho vermelho, biquinho amarelo, bode amarelo, cheiro de luna, bode vermelho, seriema, chifre de gazela, síria, acerola e peito de moça preto; Capsicum frutescens var. pirâmide ornamental, malagueta curta, malagueta comum e malaguetão e Capsicum bacccatum var. cumari e dedo de moça.

Para obtenção dos extratos foram pesados dois gramas de material fresco. Em seguida, estes foram macerados com nitrogênio líquido até que se formasse um pó e fino e posteriormente, foi transferido para Erlenmeyer com $18 \mathrm{ml}$ do extrator água. Estes foram levados à agitação em Incubadora Shaker refrigerada a 240, marca Novatecnica a 100 RPM por 24 h. Após este período esta suspensão foi filtrada em gaze e tecido de nylon a fim de retirar as partículas sólidas e depois filtrados a vácuo utilizando uma bomba de vácuo acoplada a um frasco Kitassoto e funil de Büchner para eliminar possíveis contaminações, conforme 
metodologia adaptada por Ferris et al. (1999). Os extratos obtidos foram mantidos congelados até a realização dos ensaios.

\section{Ensaios de antibiograma}

A atividade antifúngica dos extratos foi testada por meio do método de difusão em poços, vertendo o meio BDA (Batata-Dextrose-Ágar) semissólido em placas de Petri e após sua solidificação foram feitos cinco poços equidistantes com $0,5 \mathrm{~cm}$ de diâmetro e em cada um deles foi adicionado alíquotas $10 \mu \mathrm{L}$ de extrato e no centro da placa foi adicionado um disco de micélio de $0,5 \mathrm{~cm}$ de diâmetro do patógeno. As placas foram vedadas e colocadas em incubadora B.O.D. A análise dos resultados foi realizada por meio de observação dos halos de inibição a partir de 24 horas após a incubação, medindo o diâmetro dos halos no sentido longitudinal e transversal com auxílio de paquímetro digital. A observação de eventuais halos de inibição do crescimento micelial fúngico nas placas foram comparados com o grupo controle, contendo água e fungicida Azoxistrobina (0,6 g/L) para Rhizoctonia e Tiabendazol (2,5ml/l) para Sclerotium rolfsii.

Com base nos resultados obtidos, foram selecionados os cinco melhores extratos e, a partir destes foram produzidos extratos diluídos nas proporções de 1/100, 1/1000, 1/10.000 1/100.000 e 1/1000.000, com o objetivo de identificar a menor fração ativa dos extratos. Para os testes in vitro o delineamento experimental utilizado foi o inteiramente casualizado, com 25 tratamentos, dois patógenos e quatro repetições, os resultados obtidos por meio da análise de variância e comparação de médias pelo teste Scott Knott a $5 \%$ de probabilidade.

\section{Ensaios in vivo em folhas destacadas}

Para a avaliação da severidade da doença, folhas de feijoeiro da variedade Carioca BRS pontal foram destacadas de plântulas cultivadas em casa de vegetação com 12 dias após a emergência, lavadas com água destilada, secas em papel toalha e acondicionadas em caixas do tipo Gerbox ${ }^{\circledR}$ de $11,5 \mathrm{~cm}^{2}$ contendo esponja, papel de $10 \mathrm{~mm}$ cada e uma tela preta de $8 \mathrm{~cm}^{2}$ contendo de $15 \mathrm{ml}$ de água destilada para manutenção da umidade das folhas (DHINGRA et al., 1995).

A inoculação foi feita pulverizando-se, com o auxílio de um borrifador, a face superior das folhas 250 $\mu \mathrm{L}$ de suspensão de micélios, ajustadas à concentração de $1 \times 10^{6}$ frag.micélios. $\mathrm{ml}^{-1} \mathrm{e}$, em seguida, incubadas em câmaras tipo B.O.D. com temperatura de 25 oC por um período de 24 h, em regime de 12 horas claro/escuro. Após esse período, aplicou-se nas folhas $250 \mu \mathrm{L}$ dos extratos, até a cobertura total da área foliar. Em seguida as caixas gerbox foram novamente fechadas e recolocadas nas câmaras B.O.D. Estas foram diariamente avaliadas e se quantificou as folhas fotografando-as com câmera digital e armazenando as fotos para análise da severidade a posteriori. 0 experimento foi encerrado 96 horas após a incubação das folhas inoculadas, quando a severidade no controle atingiu seu auge a $100 \%$.

O delineamento experimental utilizado foi o inteiramente casualizado com 25 tratamentos e seis repetições, sendo cada parcela constituída por uma caixa de tipo Gerbox ${ }^{\circledR}$ contendo uma folha destacada. Os dados obtidos foram submetidos à análise de variância e teste de agrupamento de médias por meio do 
programa AFsoft ${ }^{\circledR}$ (SILVA et al., 2009).

\section{RESULTADOS E DISCUSSÃO}

A partir dos dados obtidos nos ensaios in vitro com extratos aquosos de sementes, realizou-se a análise de variância - ANOVA, para testar a hipótese de existência de pelo menos um extrato com efeito biológico mensurado a partir do percentual de inibição de crescimento micelial (tabelas 1 e 2).

Tabela 1: Resumo da análise de variância (ANOVA) dos ensaios de avaliação do efeito inibitório in vitro de extratos de pimentas contra Rhizoctonia solani $\left(\mathrm{mm}^{2}\right)$.

\begin{tabular}{|c|c|c|c|c|}
\hline FV & GL & SQ & QM & $\mathbf{F}$ \\
\hline TRATAMENTOS & 24 & $1,4 \times 10^{7}$ & $5,8 \times 10^{5}$ & $10,740 * *$ \\
\hline Extratos & 22 & $8,5 \times 10^{6}$ & $3,9 \times 10^{5}$ & $7,124 * *$ \\
\hline Testemunha & 1 & $4,5 \times 10^{6}$ & $4,5 \times 10^{6}$ & $83,649 * *$ \\
\hline Extratos vs. Testemunha & 1 & $9,5 \times 10^{5}$ & $9,5 \times 10^{5}$ & $17,389 * *$ \\
\hline Resíduo & 75 & $4,1 \times 10^{6}$ & $5,4 \times 10^{4}$ & --------- \\
\hline Total & 99 & ---------- & $1,8 \times 10^{7}$ & ---------- \\
\hline MÉDIA geral & ---------- & ---------- & $1,0 \times 10^{3}$ & ---------- \\
\hline MÉDIA dos extratos & --------- & --------- & $1,1 \times 10$ & --------- \\
\hline MÉDIA H2O & --------- & --------- & 0,01 & ---------- \\
\hline MEDIA FUNGICIDA & --------- & --------- & $2,1 \times 10^{4}$ & --------- \\
\hline CV(\%) & ---------- & ---------- & 2,1 & ---------- \\
\hline
\end{tabular}

FV: fonte de variação, GL: graus de liberdade, SQ: soma de quadrados, QM: quadrado médio, F: teste $F, C V$ (\%): coeficiente de variação percentual.

Tabela 2: Resumo da análise de variância (ANOVA) dos ensaios de avaliação do efeito inibitório in vitro de extratos de pimentas contra Sclerotium rolfsii $\left(\mathrm{mm}^{2}\right)$.

\begin{tabular}{|c|c|c|c|c|}
\hline FV & GL & SQ & QM & $\mathbf{F}$ \\
\hline TRATAMENTOS & 20 & $6,1 \times 10^{5}$ & $3,0 \times 10^{5}$ & $11,740 * *$ \\
\hline Extratos & 18 & $5,7 \times 10^{6}$ & $3,1 \times 10^{5}$ & $11,6997 * *$ \\
\hline Testemunha & 1 & $1,8 \times 10^{5}$ & $1,8 \times 10^{5}$ & $6,9503 * *$ \\
\hline Extratos vs. Testemunha & 1 & $3,0 \times 10^{5}$ & $3,0 \times 10^{5}$ & $11,2154 * *$ \\
\hline Resíduo & 63 & $1,7 \times 10^{6}$ & $2,7 \times 10^{4}$ & --------- \\
\hline Total & 83 & ---------- & $7,8 \times 106$ & ---------- \\
\hline MÉDIA geral & --------- & --------- & 340 & --------- \\
\hline MÉDIA dos extratos & --------- & ---------- & 3,60 & --------- \\
\hline MÉDIA H2O & --------- & --------- & 0,01 & --------- \\
\hline MEDIA FUNGICIDA & --------- & --------- & 3,08 & --------- \\
\hline CV(\%) & ---------- & ---------- & 4,80 & ---------- \\
\hline
\end{tabular}

FV: fonte de variação, GL: graus de liberdade, SQ: soma de quadrados, QM: quadrado médio, F: teste $F$, CV (\%): coeficiente de variação percentual.

De acordo com o teste $\mathrm{F}$ da análise de variância, a fonte de variação extratos foi significativa a $1 \%$ de probabilidade, indicando que existe pelo menos um extrato com efeito biológico sobre o crescimento dos fungos mostrando precisão nos resultados. Isso indica que existe pelo menos um extrato com resposta biológica (inibição) diferente dos demais.

Resultados semelhantes foram observados por Matos (2011) que trabalhando com extratos aquosos de sementes e de pimentas Capsicum spp. obteve resultados eficazes no controle in vitro de Rhizoctonia solani com as variedades 'dedo de moça', 'Pimenta amarela', e 'pimenta dos desejos'.

Lima (2012) trabalhando com diversos extratos dentre eles semente de pimenta biquinho (Capsicum chinense Jack.) observou que o mesmo apresentou eficiência em controlar Fusarium ssp., Fusarium solani f. sp. cucurbitae e Fusarium oxysporum f. sp. phaseoli. Para a classificação dos melhores tratamentos, realizou- 
se o teste de Scott Knott a $5 \%$ de probabilidade no qual se obteve diferentes grupos de inibição para os fungos $R$. solani e S. rolfsii conforme descrito na tabela 3 e 4.

Tabela 3: Médias dos halos de inibição em $\mathrm{mm}^{2}$ de Rhizoctonia solani, agrupados de acordo com o teste de Scott Knott a $5 \%$ de probabilidade.

\begin{tabular}{|c|c|}
\hline Extratos & Área $\left(\mathrm{mm}^{2}\right)$ \\
\hline Jumbinho & $2332.19 a$ \\
\hline Jariza & $1446.17 b$ \\
\hline Bode vermelho & $1351.67 b$ \\
\hline Bode amarelo & $1266.51 b$ \\
\hline Seriema & $1241.29 b$ \\
\hline Acerola & $1205.78 b$ \\
\hline Malagueta mexicana & $1189.57 b$ \\
\hline Seriema & $1156.43 b$ \\
\hline Pirâmide ornamental & $1097.12 c$ \\
\hline Chifre de gazela & $1093.81 c$ \\
\hline Cheiro de luna & $1088.98 c$ \\
\hline Biquinho vermelho & $1058.85 c$ \\
\hline Malagueta curta & $1051.62 c$ \\
\hline Peito de moça preto & $989.23 c$ \\
\hline Biquinho amarelo & $988.78 \mathrm{c}$ \\
\hline Vulcão & $943.19 c$ \\
\hline Jurema & $938.20 c$ \\
\hline Malagueta comum & $931.83 c$ \\
\hline Peito de moça & $918.87 \mathrm{c}$ \\
\hline Cumari & $884.98 c$ \\
\hline Malaguetão & $879.39 c$ \\
\hline Dedo de moça & $863.49 c$ \\
\hline Pimenta dos desejos & 799.79c \\
\hline \multicolumn{2}{|c|}{ 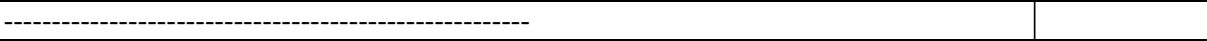 } \\
\hline Controle Água & 0,01 \\
\hline Controle Fungicida & 21367 \\
\hline
\end{tabular}

Médias seguidas pelas mesmas letras maiúsculas na VERTICAL constituem grupo estatisticamente homogêneo.

Tabela 4: Médias dos halos de inibição em $\mathrm{mm}^{2}$ de Sclerotium rolfsii, agrupados de acordo com o teste de Scott Knott a $5 \%$ de probabilidade.

\begin{tabular}{|l|l|}
\hline Extratos & Área $\left(\mathrm{mm}^{2}\right)$ \\
\hline Jumbinho & $1164.06 \mathrm{a}$ \\
\hline Acerola & $930.87 \mathrm{~b}$ \\
\hline P. dos desejos & $797.20 \mathrm{c}$ \\
\hline Jariza & $639.01 \mathrm{~d}$ \\
\hline Biquinho amarelo & $334.22 \mathrm{e}$ \\
\hline Cheiro de luna & $323.80 \mathrm{e}$ \\
\hline Cumari & $270.77 \mathrm{e}$ \\
\hline Malagueta mexicana & $259.71 \mathrm{e}$ \\
\hline Malaguetão & $251.27 \mathrm{e}$ \\
\hline Bode vermelho & $248.14 \mathrm{e}$ \\
\hline Seriema & $211 \mathrm{f}$ \\
\hline Chifre de gazela & $203.78 \mathrm{f}$ \\
\hline Biquinho vermelho & $201.80 \mathrm{f}$ \\
\hline Peito de moça preto & $193.53 \mathrm{f}$ \\
\hline Vulcão & $177.61 \mathrm{f}$ \\
\hline Pirâmide ornamental & $160.85 \mathrm{f}$ \\
\hline Peito de moça & $158.91 \mathrm{f}$ \\
\hline Seriema & $119.54 \mathrm{f}$ \\
\hline Bode amarelo & $64.96 \mathrm{f}$ \\
\hline-------------------------------------- & \\
\hline Controle água & 0,01 \\
\hline Controle Fungicida & 308,4 \\
\hline
\end{tabular}

Médias seguidas pelas mesmas letras minúsculas na VERTICAL constituem grupo estatisticamente homogêneo.

Os resultados demonstram que o extrato aquoso de pimenta jumbinho apresentou inibição do 
crescimento micelial superior ao efeito do fungicida com ambos os fungos, enquanto que os extratos aquosos de sementes de 'Acerola', 'pimenta dos desejos', 'Jariza', 'Biquinho Amarelo', e 'Cheiro de luna' apresentaram alta inibição somente contra o fungo S. rolfsii. Os demais extratos apresentaram algum halo de inibição, porém inferiores ao fungicida padrão utilizado. Se, no entanto, forem comparados estes resultados com o controle com água, todos apresentaram resultados com certa capacidade inibitória.

Venturoso et al. (2011), testando extratos aquosos de cravo-da-índia, alho e canela com relação ao crescimento micelial, constatou atividade antifúngica sobre Aspergillus sp., Penicillium sp., C. kikuchii, Colletotrichum sp., F. solani e Phomopsis sp.. A inibição proporcionada pelos extratos foi observada a partir do terceiro dia de incubação e persistiu até o final das avaliações, assim como Silva et al. (2009), testando extrato de cravo-da-índia obteve resultado em $100 \%$ de inibição sobre o crescimento de $C$. gloeosporioides. Nos ensaios de inibição com extratos diluídos foi possível observar que mesmo em diluições de até 1:10.000 os extratos de pimenta jumbinho, jariza e seriema se mostraram eficazes contra o fungo $R$. solani conforme figura 1.

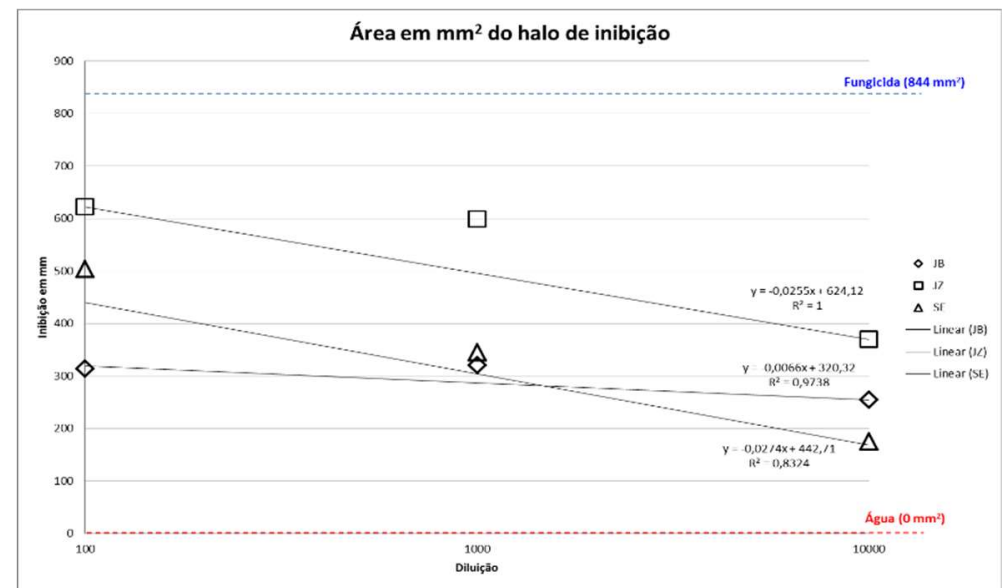

Figura 1: Curva de correlação entre a dose do extrato testado e a inibição de Rhizoctonia solani in vitro.

Nos ensaios de inibição com extratos diluídos contra o fungo $S$. rolfssi foi possível observar que mesmo em diluições maiores de 1:10.000 os extratos de pimenta jumbinho e biquinho amarelo se mostraram eficazes contra o fungo $R$. solani conforme figura 2 .

Esses resultados se assemelham com os de Bernardo et al. (2015) os quais trabalhando com extratos de carqueja para inibição de A. alternata, C. graminicola, Phytophthora sp. e R. solani e manjericão para S. rolfsii observou que as maiores inibições do crescimento micelial ocorreram com o aumento das concentrações de cada extrato, apresentando um comportamento dose dependente, isto é, com o aumento da concentração de cada extrato, maior foi a inibição do crescimento dos fito patógenos.

O mesmo efeito pode ser observado em outros estudos, nos quais, testando efeito de extratos Capsicum frutescens contra patógenos de solo, entre eles Fusarium sp., observaram que a pimenta foi capaz de inibir $100 \%$ do crescimento micelial e esporulação do fungo quando em doses de 1500 a 300 ppm do extrato bruto. 


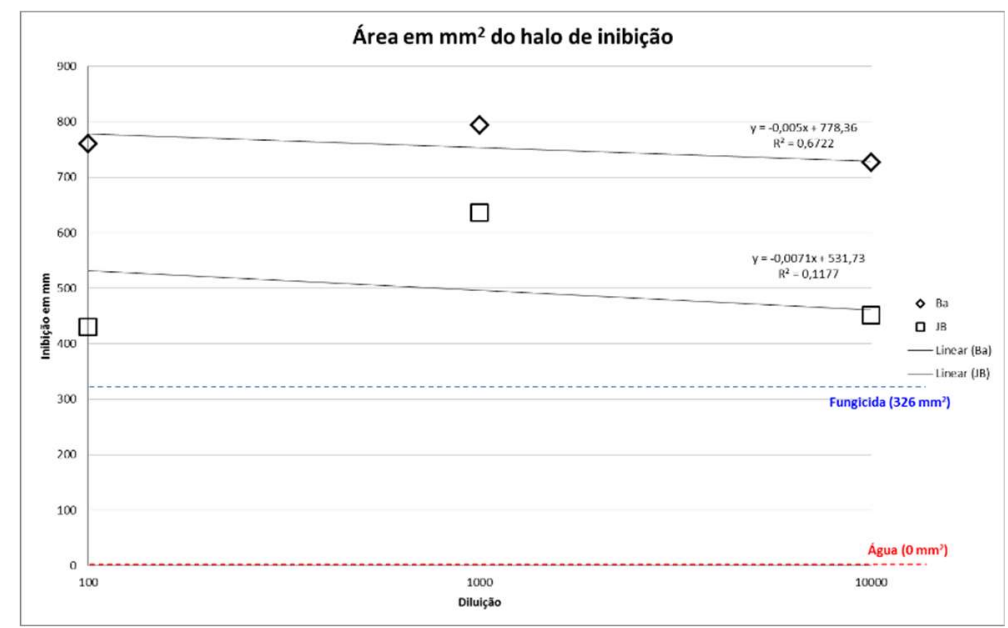

Figura 2: Curva de correlação entre a dose do extrato testado e a inibição de Sclerotium rolfsii in vitro.

Matos (2011) testando extratos de pimenta em diferentes concentrações observou que mesmo em doses maiores $(1 / 10.000)$ os extratos se mostraram eficientes para o controle de $R$. solani, não havendo diferença significativa entre as doses testadas, mesmo quando comparadas com o tratamento fungicida. Vieira Junior et al. (2016) trabalhando com diferentes extratos de pimenta (Capsicum sp.) sobre o crescimento micelial de Rhizoctonia solani observaram que, nos ensaios de diluição 1:1000 e 1:10.000, todos apresentaram halo de inibição contra o fungo testado sendo mais eficaz na maior concentração.

Os resultados obtidos por meio das avaliações in vivo com folhas destacadas foram mensurados se utilizando o programa $\mathrm{AFsoft}^{\circledR}$. Os resultados obtidos demonstram uma baixa severidade nos tratamentos, quando comparados com o controle com água. Desses, destacam-se os extratos aquosos de 'Cumari' e 'Malagueta Curta', que apresentaram severidade máxima às 96 horas estatisticamente similares ao controle com fungicida conforme tabela 5 .

Tabela 5: Severidade a Rhizoctonia solani avaliado em folhas de feijão inoculadas em gerbox ${ }^{\circledR}$.

\begin{tabular}{|c|c|c|c|c|c|c|}
\hline \multirow[t]{2}{*}{ Extratos } & \multirow[t]{2}{*}{ Tratamento } & \multicolumn{4}{|l|}{ Tempo } & \multirow[t]{2}{*}{ total } \\
\hline & & 24 & 48 & 72 & 96 & \\
\hline Cumari & 10 & $1.35 a$ & $3.88 \mathrm{~b}$ & $14.78 b$ & $29.28 d$ & 12.3 \\
\hline Fungicida & 25 & $2.25 a$ & $11.17 \mathrm{~b}$ & $20.83 b$ & $22.5 d$ & 14.2 \\
\hline Malag. Curta & 16 & $0.88 a$ & $7.28 b$ & $19.5 b$ & $34.5 d$ & 15.5 \\
\hline Vulcão & 9 & $1.4 a$ & $8.33 b$ & $20.5 b$ & $48.33 c$ & 19.6 \\
\hline Jurema & 14 & $1.12 \mathrm{a}$ & $4.85 b$ & $21.18 \mathrm{~b}$ & $59.18 b$ & 21.6 \\
\hline Jumbinho & 13 & $1.6 a$ & $8.35 b$ & $20.5 b$ & $50.83 c$ & 20.3 \\
\hline Malag. Comum & 15 & $0.8 a$ & $10.5 b$ & $22.17 b$ & $48 c$ & 20.4 \\
\hline Acerola & 1 & $0.88 a$ & $7.25 b$ & $31 b$ & $61.33 b$ & 25.1 \\
\hline Biq Vermelho & 3 & $0.95 a$ & $5.58 b$ & $33.33 a$ & $65.83 b$ & 26.4 \\
\hline Bode Amarelo & 4 & $1.17 a$ & $5.5 b$ & $29.17 a$ & $78.33 a$ & 28.5 \\
\hline Cheiro de Luna & 6 & $0.12 a$ & $8.83 b$ & $32 a$ & $72.5 a$ & 28.4 \\
\hline Malaguetão & 18 & $1.02 \mathrm{a}$ & $19 a$ & $31.33 a$ & $60 \mathrm{~b}$ & 27.8 \\
\hline Síria & 8 & $2.28 a$ & $16 a$ & $30.33 a$ & $62.5 b$ & 27.8 \\
\hline Desejos & 21 & $2.67 a$ & $17.5 a$ & $38 a$ & $60 b$ & 29.5 \\
\hline Biq. Amarelo & 2 & $0.12 a$ & $10 \mathrm{~b}$ & $36 a$ & $87.5 a$ & 33.4 \\
\hline Pirâmide Ornamental & 22 & $0.1 a$ & $14.33 a$ & $36.67 a$ & $72.5 a$ & 30.9 \\
\hline Malag. Mexicana & 17 & $1 a$ & $18.83 a$ & $37.5 a$ & $70.83 b$ & 32.0 \\
\hline $\mathrm{H}_{2} \mathrm{O}$ & 24 & $2.17 a$ & $9 \mathrm{~b}$ & $36.67 a$ & $88.33 a$ & 34.0 \\
\hline Dedo de Moça & 11 & $1.22 a$ & $16.33 a$ & $38.83 a$ & $72.5 a$ & 32.2 \\
\hline Jariza & 12 & $0.56 a$ & $10.2 b$ & $41 a$ & $85 a$ & 34.2 \\
\hline Chifre de Gazela & 7 & $0.83 a$ & $12.17 \mathrm{~b}$ & $47.5 a$ & $79.17 a$ & 34.9 \\
\hline Bode Vermelho & 5 & $1 a$ & $12.5 a$ & $44.17 a$ & 83.33a & 35.3 \\
\hline Seriema & 23 & $0.18 a$ & $23.67 a$ & $47.5 a$ & $85 a$ & 39.1 \\
\hline
\end{tabular}




\begin{tabular}{|l|l|l|l|l|l|l|}
\hline Peito de Moça & 19 & $1.67 a$ & $25.83 a$ & $50 a$ & $80 a$ & 39.4 \\
\hline Peito Moça Preto & 20 & $7.5 a$ & $23.5 a$ & $61.67 a$ & $60 b$ & 38.2 \\
\hline & & & & & & \\
\hline
\end{tabular}

Médias seguidas pelas mesmas letras minúsculas na VERTICAL constituem grupo estatisticamente homogêneo.

Com isso, pode-se observar que os ensaios in vivo em folhas destacadas são bastante promissores no sentido de determinar a eficiência de extratos no controle de doenças, uma vez que as condições oferecidas para o patógeno colonizar a planta como temperatura e umidade elevadas são ótimas favorecendo a expressão máxima da doença nos tecidos da planta. Isso pode ser constatado nos trabalhos realizados por Carmo et al. (2015) que demostrou que a doença Antracnose se tornou mais severa em condições controladas em folhas destacadas do que em condições de campo.

O mesmo pode ser observado se compararmos os resultados obtidos neste trabalho com de outro autor realizado em 2012, em que os dados em testes com gerbox atingiram próximo a $100 \%$, enquanto que a campo e em casa de vegetação os dados não chegaram a 50\%, demostrando que o método de seleção está adequado ao tipo de trabalho a que se destina.

Entretanto, também foi possível observar que o efeito da inibição dos extratos Cumari, Malagueta curta, Malagueta comum, Seriema e cheiro de luna, sobre o progresso da doença (figura 3) só se deu até 72 horas após a aplicação do mesmo, demonstrando a perda da eficiência destes extratos após este período. Isto indica que haveria a necessidade de reaplicação do produto após 72 horas ou a incorporação de alguma substância que atuasse como espalhante adesivo e auxiliasse na fixação do extrato na superfície da folha, evitando seu escorrimento, devido ao excesso de umidade formado dentro da câmara. Este tipo de ação é notadamente implementada na aplicação de fungicidas comerciais, especialmente em regiões onde chove muito e há o risco de escorrimento do produto das folhas para o solo (KIMATI et al., 2005).

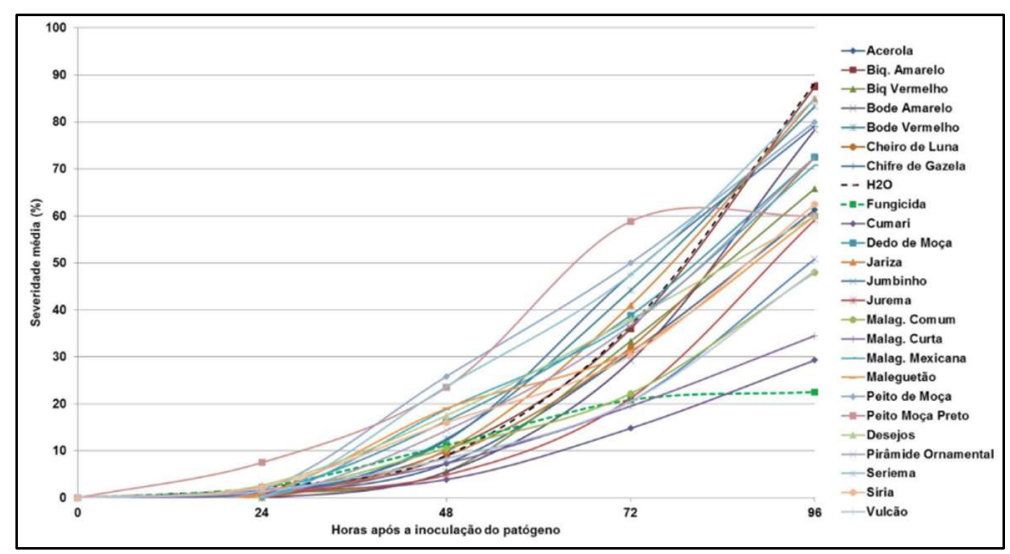

Figura 3: Curva de progresso da mela do feijoeiro comum em função do extrato testado em ensaios in vivo em folha destacada.

Pode-se observar que os extratos testados foram capazes de reduzir o progresso da doença e a severidade máxima observada. Consequentemente este efeito se refletiu no acúmulo de severidade ao longo do tempo, nos diferentes tratamentos, quando comparados com o controle com fungicida. Isto pode ser observado na figura 4, determinado pela área abaixo da curva de progresso de doença, com valores inferiores ao controle com água na maioria dos tratamentos e especialmente as pimentas Cumari e Malagueta curta quando comparadas ao controle com o fungicida. 


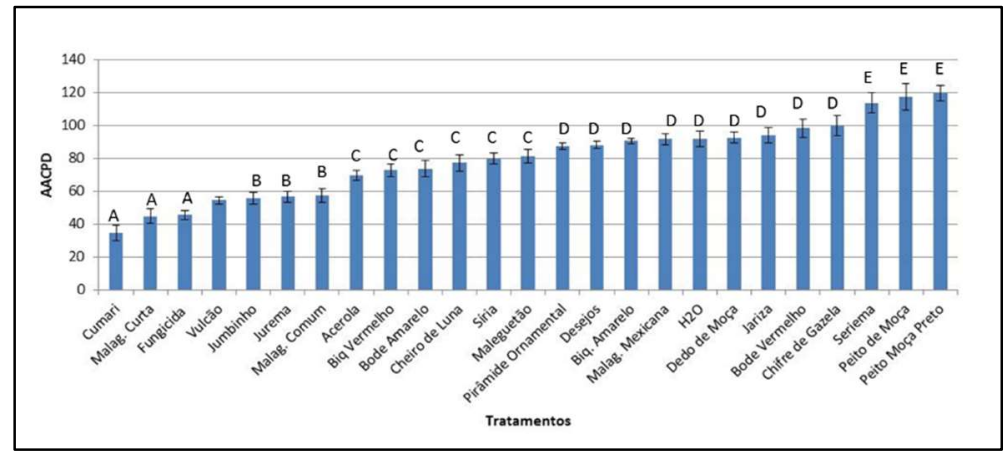

Figura 4: Área abaixo da curva de progresso da mela do feijoeiro em ensaio in vivo em folhas destacadas.

\section{CONCLUSÕES}

Os extratos de sementes de pimentas se mostraram eficientes na inibição dos patógenos até na concentração 1:10.000 para o fungo $R$. solani e de até 100.000 para o fungo $S$. rolfsii. No ensaio in vivo em folhas destacadas, 13 extratos apresentaram eficiência no controle da mela, sendo que os extratos obtidos a partir de pimenta Cumari e Malagueta curta apresentaram efeitos de controle significativamente semelhantes aos do fungicida comercial. Extratos vegetais podem ser utilizados futuramente como fonte de novas moléculas bioativas para o controle desses patógenos, visto que os mesmos mostraram resultados promissores no controle destes.

AGRADECIMENTOS: a Empresa Brasileira de Pesquisa Agropecuária - CPAFRO, a Universidade Federal de Rondônia em especial ao Programa de Pós-Graduação em Ciências Ambientais e a Coordenação de Aperfeiçoamento de Pessoal de Nível Superior - CAPES.

\section{REFERÊNCIAS}

BERNARDO, R.; SCHWAN-ESTRADA, K. R. F.; STANGARLIN, J. R; OLIVEIRA, J. S. B.; CRUZ, M. E. S.. Sobre o crescimento micelial de fungos fitopatogênicos. Scientia Agraria Paranaensis, Marechal Cândido Rondon, v.14, n.2, p.89-93, 2015.

CARMO, M. D. S.; CARVALHO, E. M. S.; GOMES, R. L. F.; LOPES, A. C. A.; CAVALCANTE G. R. S.. Avaliação de acessos de feijão-fava, para resistência a Colletotrichum truncatum, em condições de folhas destacadas e campo. Summa Phytopathol., Botucatu, v.41, n.4, p.292-297, 2015.

DHINGRA, O. D.; SINCLAIR, J. B.. Basic Plant Pathology Methods. Boca Raton: CRC Press, 1995.

FAO. Organização das Nações Unidas para a Alimentação e Agricultura. Base de dados Faostat. FAO, 2017.

FERNANDES, C. F.; VIEIRA JÚNIOR, J. R.; SILVA, D. S. G.; REIS, N. D.; ANTUNES JÚNIOR, H.. Mecanismos de defesa de plantas contra o ataque de agentes fitopatogênicos. 2009.

FERRIS, H.; ZHENG, L.. Plant sourcers of Chinese herbal remedies: effects on Pratylenchus vulnus and Meloidogyne javanica. Journal of Nematology, Marceline, v.31, p.241263, 1999.
KIMATI, H.; AMORIM, L.; BERGAMIN FILHO, A.; CAMARGO, L. E. A.; RESENDE, J. A. M.. Manual de fitopatologia: doenças de plantas. 4 ed. Piracicaba: Ceres, 2005.

LIMA, F. C.. Efeito de extratos de plantas no controle de Fusarium sp. Monografia (Graduação em Agronomia) Faculdades Integradas Aparício Carvalho, Porto Velho, 2012.

RAVA, C. A.. Doenças Fúngicas do solo. Brasília, 2011.

MACÊDO, C. G.; SOUSA, B. C. M.; FRAGA, S. S.; LOURIDO, K. A.; LUSTOSA, D. C.; SILVA, E. O.; CASTRO, K. C. F.. Fotoquímica e atividade antifúngica do extrato de folhas de Piper marginatum no controle de fitopatógenos. Revista Ibero-Americana de Ciências Ambientais, v.9, n.6, p.70-77, 2018. DOI: http://doi.org/10.6008/CBPC21796858.2018 .006 .0009

MATOS, S. I.. Efeito de extratos de pimenta do gênero Capsicum no controle de Rhizoctonia solani Kum causador da teia micélica do feijoeiro comum (Phaseolus vulgaris L.). Monografia (Graduação em Ciências Biológicas) - Faculdade São Lucas, Porto Velho, 2011.

RIGOTTO, R. M.; VASCONCELOS, D. P.; ROCHA, M. M.. Uso de agrotóxicos no Brasil e problemas para a saúde pública. Caderno Saúde Pública, Rio de Janeiro, v.30, n.7, p.1-3, 
2014. DOI: http://dx.doi.org/10.1590/0102-311XPE020714

SANTOS, C. A. B.; SILVA, A. P. M.. Extratos vegetais de plantas daninhas contra o pulgão aphis craccivora koch 1854, no feijão vigna unguiculata (I.) walp. Revista IberoAmericana de Ciências Ambientais, Aquidabã, v.6, n.2, p.6975, 2015. DOI: http://dx.doi.org/10.6008/SPC21796858.2015.002.0005

SARTORATO, A.; RAVA, C. A.; FARIA, J. C.. Cultivo do Feijoeiro Comum Doenças e métodos de controle. Goiânia: Embrapa Arroz e Feijão, 2003.

SILVA, D. J. B.; JORGE, L. A. C.. AFSOFT: Software para análise foliar. In: SIMPÓSIO INTERNACIONAL DE INICIAÇÃO CIENTÍFICA DA USP, 17. Anais. São Carlos, 2009.
STANGARLIN, J. R.; KUHN, O. J.; TOLEDO, M. V.; PORTZ, R. L.; SCHWANESTRADA, K. R. F.; PASCHOLATI, S. F.. A defesa vegetal contra fitopatógenos. Scientia Agraria Paranaenis, v.10, n.1, p.18-46, 2011

VENTUROSO, L. R.; BACCHI, L. M. A.; GAVASSONI, W. L.. Atividade antifúngica de extratos vegetais sobre $o$ desenvolvimento de fito patógenos. Summa Phytopathologica, v.37, n.1, p.18-23, 2011.

VIEIRA JUNIOR, J. R.; FERNANDES, C. F.; ALVES, R. C.; FONSECA, A. S.; FREIRE, T. C.. Extratos de pimentas (Capsicum spp.) para inibição do crescimento micelial in vitro de Rhizoctonia solani Kuhn. Enciclopédia Biosfera, Centro Científico Conhecer, Goiânia, v.13 n.23, p.14, 2016.

A CBPC - Companhia Brasileira de Produção Científica (CNPJ: 11.221.422/0001-03) detém os direitos materiais desta publicação. Os direitos referem-se à publicação do trabalho em qualquer parte do mundo, incluindo os direitos às renovações, expansões e disseminações da contribuição, bem como outros direitos subsidiários. Todos os trabalhos publicados eletronicamente poderão posteriormente ser publicados em coletâneas impressas sob coordenação da Sustenere Publishing, da Companhia Brasileira de Produção Científica e seus parceiros autorizados. Os (as) autores (as) preservam os direitos autorais, mas não têm permissão para a publicação da contribuição em outro meio, impresso ou digital, em português ou em tradução. 